\title{
Nurses' self-evaluations of human immunodeficiency virus (HIV) staff educational programs
}

\author{
Vida Mockiené1 ${ }^{1}$ Tarja Suominen², Maritta Valimaki³ ${ }^{2}$ Arturas Razbadauskas ${ }^{1}$, Arvydas \\ Martinkenas' ${ }^{1}$, Marija Trush'1 \\ 1. Faculty of Health Sciences, University of Klaipeda, Lithuania. 2. School of Health Sciences, Nursing Science, University \\ of Tampere, Finland. 3. Department of Nursing Science, University of Turku, Finland.
}

Correspondence: Tarja Suominen. Address: School of Health Sciences, Nursing Science, University of Tampere, Finland. Email: tarja.suominen@uta.fi

Received: February 7, 2014

DOI: $10.5430 /$ jnep.v4n10p51
Accepted: July 7, 2014

URL: http://dx.doi.org/10.5430/jnep.v4n10p51

\section{Abstract}

This study looks to describe nurses' self-evaluations of staff education programs relating to HIV and acquired immune deficiency syndrome (AIDS). Two different education programs were employed in three Lithuanian hospitals: a 2-day workshop and the distribution of written materials were used in one hospital, and only the distribution of written materials in another. A third hospital was chosen for control purposes. A descriptive and comparison study was undertaken with two experimental groups (first group, $n=63$, second group, $n=63$ ), and one control group $(n=59)$. Nurses in the first group were more satisfied with the program methods $(p<.001)$, duration $(p<.001)$, and also the value for them $(p=.010)$.

The nurses' satisfaction with the education program related to their background factors was mostly related to the nurses' working area. Nurses from the first group who worked in a gynecological ward were more satisfied with the information they received on HIV transmission than those drawn from a primary health care center, $(p=.038)$, they were also more satisfied with the program's duration than nurses from medical ward $(p=.003)$. Program evaluation (from 0 to 10$)$ was affected by the nurses' working areas. The nurses in the first group who worked in the gynecological ward evaluated the program with the higher mark than the nurses from the surgical ward. The result was statistically significant $(p=.004)$. Nurses from the second group (provided with only written material) who worked in a primary health care center were more satisfied with the HIV and AIDS disease content, than nurses who worked in the gynecological ward $(p=.033)$.

The comparison between the two education groups evaluating the education program about HIV and AIDS in the interval scale from 0 to 10 was statistically significant $(p=.016)$. The nurses of the first group evaluated the education program very highly.

Most suggestions concerned program methods and program duration when asked the ways for further developed education programs. The nurses of the first group (2-day workshop and the provision of written materials) indicated that they would like to have courses with lectures using more visual means of presenting material, more discussions, and that the courses should be longer. We can conclude that special courses are needed for nurses to improve their knowledge of HIV and AIDS.

\section{Key words}

Education intervention, Evaluation, Nurse, HIV, Satisfaction 


\section{Introduction}

Although nursing literature has stressed the importance of continuing education since the beginnings of the profession ${ }^{[1]}$, the importance of ongoing continuing education and professional development for nurses is increasingly recognized ${ }^{[2]}$. The current and projected demands for nurses and nursing services worldwide, coupled with dramatic changes in the delivery of health care, require nurses with greater levels of knowledge, education and skills ${ }^{[3]}$. Continuing education has been noticed to have an impact on different issues such as nursing practice ${ }^{[1,4-7]}$, patient outcomes ${ }^{[1,8]}$, nurses' knowledge levels ${ }^{[1,7,9]}$ and professional growth ${ }^{[10,11]}$. Educational meetings are one of the most common types of continuing education for health professionals, and an important aim of continuing education is to influence professional practice ${ }^{[4]}$. It is therefore necessary for nurses to perceive a clear relationship as existing between continuing education, improved client care and nursing practice.

The literature is abundant with calls for a curriculum reform in nursing education, advocating curricula that are responsive to changes in the health care delivery system, are research-based and collaborative, and apply pedagogical innovation ${ }^{[13]}$. Many researchers ${ }^{[6,14]}$ have indicated that training should head in new directions, some of which include personal experience, group support, grand rounds, hospital-wide continuing education programs, professional organization-based continuing education programs, on-line educational programs, and journal clubs. Such initiatives are useful in that they allow participants to assist each other in understanding material and help learners understand how the things they learn can be applied to the workplace.

In today's society, hospital inpatients are more acutely ill and present with multifaceted and complex health problems that necessitate ongoing high-quality nurse education ${ }^{[17]}$. Education is essential in the area of nursing patients living with HIV or AIDS, because nurses form the front line of their care, prevention and advocacy, so reducing the risk of HIV infection among their clients and contributing to the improvement and quality of care delivered ${ }^{[21]}$.

The effective education of nurses relating to HIV and care for People Living with AIDS (PLWA) has not been extensively researched and there is still a need to develop nurse education so that they could undertake roles such as HIV prevention leaders. The barriers which inhibit individual health workers from becoming involved in HIV prevention have been identified in previous research ${ }^{[24,25]}$. These include knowledge deficit, HIV and AIDS stigmatizing attitudes, and a reluctance to discuss HIV, AIDS, sexuality, and aspects of risky behaviour in the client's personal life. Thus, it is important to understand the views of health care professionals and their perspective on education related to HIV and AIDS. This study therefore places a special emphasis on the self-evaluation of HIV and AIDS related staff educational programs.

\section{Purpose and research questions}

The purpose of this study is to describe nurses' self-evaluations of HIV and AIDS related education programs. The specific research questions were:

1) How should such education be organized?

a) What is the best source of information about HIV and AIDS?

b) What is the best duration for this type of education program?

2) How satisfied were nurses with these education programs?

3) How was nurse satisfaction related to background factors?

4) How should education programs be further developed? 


\section{Materials and methods}

\subsection{Education program}

Two different education programs were used: a 2-day workshop including the distribution of written materials was used in one hospital, and only the distribution of written materials was used in another hospital. An additional hospital was used for control purposes.

The education session provided for the first group consisted of a 2-day workshop and the provision of written materials. The workshops lasted 13 hours in total, including 1 hour for an introduction to the research and instructions on how to complete the questionnaire. The taught elements included: lectures, group discussions, a conversation with people living with HIV, a film "Health care workers and HIV and AIDS", lecture handouts and the distribution of written materials. The film was based on the educational aspect of how to avoid contamination at work. The film lasted for about 60 minutes and was originally created in Finland. It was made available in the Lithuanian language by the Lithuanian AIDS Centre. The content areas were: HIV epidemiology and history, prevention, transmission, HIV treatment, counseling and ethical considerations. The written materials consisted of academic journal articles on the program's content area topics (20 pages).

The intervention received by the second group consisted of the same academic journal articles ( 20 pages) that were provided to the first group nurses. Additionally, the lecture handouts from the first group were also provided to the second group ( 2 pages providing new statistics for the HIV situation Lithuanian and global contexts). In total the second group participants received 22 pages of written material. The control group of nurses received no lectures or written materials. The participants from the first and second groups were also provided with continuing education credits as an incentive to participate.

\subsection{Participants and settings}

The participants were nurses registered in Lithuanian who worked in the surgical, medical, or gynecology wards of three of the largest hospitals in Lithuania, and in primary health care centers attached to the hospitals. The nurses were randomized into study groups from pools of about 300 nurses at each hospital. The minimum number of participants required per group was 55 , however, this was increased to 80 per group (as the response rate was $68.8 \%$ ), so as to allow a more robust exploration to be conducted. A total of 240 nurses were invited to participate in the study. The study utilized a descriptive and comparison design, with pre-test evaluation and a three-month repeated follow-up evaluation. The baseline sample contained 206 participants ( $15 \%$ of the invited nurses declined to participate in the study). The follow-up sample contained 185 participants ( $10 \%$ of nurses withdrew from the study).

\subsection{Data collection methods}

The baseline questionnaire consisted of background factors and questions related to the sources of nurses' views on who could best provide information about HIV infection and/or AIDS. The background factors asked were demographic: age, sex, mother-tongue, marital status, whether the respondent had children or not, and the highest level of education held. Work related background factors such as work experience in health care, current work place, work area and work experience in their present ward were also gathered. The nurses' need for information was assessed using a 5 point Likert-scale.

The follow-up questionnaire consisted of a few background questions that confirmed nurses' current workplace, work area and work experience in their present ward. In regard to the questions related to their information about HIV and AIDS, the respondents needed to evaluate how well they related to the sources of information which were made available to their study group. Their satisfaction with the chosen program was evaluated using a 5-point Likert scale. Satisfaction was measured related to the content, methods and duration of the program. Additionally, the respondents gave their opinion of 
the program on the interval scale from 0 to 10 , and an open-ended question was provided were respondents could write any suggestions for an HIV and AIDS education program for nurses.

\subsection{Ethical issues and limitations}

Following a positive statement by the research ethics board of University of Klaipeda, in Lithuania, permission to conduct the study was obtained directly from the hospitals involved. The staff was informed about the purpose of the study and the nature of voluntary and confidential participation. Written consent was obtained from all participants. The completed questionnaires were returned in sealed envelopes directly to the researchers based on ethical principles ${ }^{[27]}$.

As limitation there were some statistically significant differences between the groups, and also a change in the sample size between the baseline and follow-up data.

\subsection{Analysis}

A quantitative analysis approach was used to evaluate and interpret the numerical data. Statistical analysis was performed by using the SPSS 12.0 software package. The nurses' demographic variables and items concerning their evaluation of the education program were examined using descriptive analysis. After testing for normality, parametric and nonparametric criteria were used to compare two or more groups (ANOVA, Tukey's HSD, Mann-Whitney and Kruskal-Wallis tests). Probability values of less than .05 were interpreted as being statistically significant.

Cronbach's alpha coefficient was used to evaluate whether the items within a scale reflected or measured the same concept ${ }^{[26]}$. Two factors were detected in the results (the content and the value for participants) for the participants of the two groups. In the first group, the Cronbach's alpha coefficient in satisfaction with the content was 0.923 and 0.938 for value. In the second group it was 0.922 for content and 0.856 for value.

Nurses' suggestions for the further development of education programs were evaluated using the content analysis method. The analysis started with searching the statements provided which corresponded to the questions ${ }^{[27]}$. Content analysis can help evaluators learn more about the programs and issues involved due to its systematic approach, and has structured forms that allow the extraction of relevant information more consistently than if the same information were read only casually.

\section{Results}

\subsection{Sample characteristics}

All participating nurses were female and the majority was married and had children. The nurses varied in age from 23 to 67 years, their mean age being 43.1 ( $\mathrm{SD}=8.8$ ). The level of work experience was long and about the same numbers of nurses were drawn from surgical, medical, and gynecological units and primary health care centers attached to the hospitals. There were some statistically significant differences between the groups: the participants in the first group were youngest $(p=.016)$, held a higher level of university education $(p=.001)$ and had the least work experience $(p=.051)$ and had fewer children $(p=.46)$.

\subsection{Organization of the education}

For both groups, the best means of gathering information on HIV or/and AIDS related information was reported to be through a special course (see Table 1), determined both at baseline enquiry and follow-up. Also, the majority of nurses from both groups thought that the best information source was an academic article (see Table 1). It is important to highlight that before the education program, up to $42 \%$ of nurses of the first group believed that the best information source was from mass media, but following the education program only $23.8 \%$ of nurses held the same view. 
Table 1. The best information source about HIV/AIDS, as identified at baseline $(\mathrm{n}=206)$ and follow-up $(\mathrm{n}=185)$ between groups

\begin{tabular}{|c|c|c|c|c|c|c|}
\hline & $\begin{array}{l}\text { Totally agree } \\
(\%)\end{array}$ & Agree (\%) & $\begin{array}{l}\text { Partly agree partly } \\
\text { disagree (\%) }\end{array}$ & Disagree (\%) & $\begin{array}{l}\text { Totally disagree } \\
(\%)\end{array}$ & \multirow{2}{*}{$\boldsymbol{P}$} \\
\hline & $\begin{array}{l}\text { Baseline and } \\
\text { follow-up }\end{array}$ & $\begin{array}{l}\text { Baseline and } \\
\text { follow-up }\end{array}$ & $\begin{array}{l}\text { Baseline and } \\
\text { follow-up }\end{array}$ & $\begin{array}{l}\text { Baseline and } \\
\text { follow-up }\end{array}$ & $\begin{array}{l}\text { Baseline and } \\
\text { follow-up }\end{array}$ & \\
\hline \multicolumn{7}{|l|}{ Mass media } \\
\hline First group & $42.0 / 23.8$ & $23.2 / 33.3$ & $23.2 / 33.3$ & $13.0 / 9.5$ & $4.3 / 1.6$ & .076 \\
\hline Second group & $24.3 / 33.3$ & $32.9 / 33.3$ & $32.9 / 33.3$ & $8.6 / 3.2$ & - & .435 \\
\hline Control group & $28.6 / 30.5$ & $33.3 / 44.1$ & $21.4 / 15.9$ & $11.9 / 6.8$ & $4.8 / 1.7$ & .643 \\
\hline \multicolumn{7}{|l|}{ Scientific article } \\
\hline First group & $65.2 / 63.5$ & $29.0 / 27.0$ & $5.8 / 7.9$ & - & $0.0 / 1.6$ & .711 \\
\hline Second group & $63.8 / 71.4$ & $29.0 / 20.6$ & $2.9 / 7.9$ & $2.9 / 0.0$ & $1.4 / 0.0$ & .238 \\
\hline Control group & $60.5 / 57.6$ & $39.5 / 28.8$ & $0.0 / 10.2$ & $0.0 / 1.7$ & $0.0 / 1.7$ & .151 \\
\hline \multicolumn{7}{|c|}{ Popular literature } \\
\hline First group & $34.8 / 22.2$ & $30.4 / 34.9$ & $18.8 / 28.6$ & $15.9 / 12.7$ & $0.0 / 1.6$ & .323 \\
\hline Second group & $18.6 / 34.9$ & $37.1 / 25.4$ & $20.0 / 27.0$ & $21.4 / 11.1$ & $2.9 / 1.6$ & .096 \\
\hline Control group & $23.3 / 32.2$ & $37.2 / 33.9$ & $18.6 / 23.7$ & $16.3 / 10.2$ & $4.7 / 0.0$ & .336 \\
\hline \multicolumn{7}{|l|}{ Special Course } \\
\hline First group & $73.9 / 73.0$ & $24.6 / 15.9$ & $1.4 / 6.3$ & $0.0 / 3.2$ & $0.0 / 1.6$ & .158 \\
\hline Second group & $84.3 / 73.0$ & $15.7 / 27.0$ & - & - & - & .111 \\
\hline Control group & $74.4 / 78.0$ & $20.9 / 18.6$ & $2.3 / 1.7$ & $2.3 / 1.7$ & - & .976 \\
\hline
\end{tabular}

Note. First group (2-day workshop and written material); second group (written material). Kruskal Wallis Test - the mean difference is significant at the level of $p<.05$.

After the education program the first group of nurses evaluated the best possible program duration to be 2-5 days ( mean $=$ 3.30 , median $=3.00, \mathrm{SD}=1.15)$. The second group of nurses reported it to be more than 1 week $($ mean $=3.98$, median $=$ $4.00, \mathrm{SD}=1.55)$. The control group reported the best possible duration to be $2-5$ days $($ mean $=3.56$, median $=3.00, \mathrm{SD}=$ 1.18). The difference between the first and the second group was statistically significant $(p=.005)$.

\subsection{Nurses' satisfaction with the education program}

After the education program, the nurses of the first group assessed the education program content (see Table 2). They were more satisfied with the content areas of risk contact (61.9\%), treatment and care (61.9\%), HIV transmission (57.1\%) explanation, and disclosure and confidentiality (57.1\%). However, the nurses of this group were not satisfied coverage of the law regulating the work with HIV-positive patients (38.1\%), the explanation of ethical problems (34.9\%) or the duration of the program (41.3\%). The nurses were very satisfied with all of the methods used in the program: film, group discussion, group discussion with an HIV positive person, lectures and the provision of written materials. They were least satisfied with duration of the education program, but were very satisfied with the value it provided.

The nurses of the second group were more satisfied with the content information related to HIV transmission (68.3\%), treatment and care (66.7\%), HIV and AIDS disease (58.7\%), risk contact (58.7\%) and fear and contagion (57.1\%). They were least satisfied with the methods (20.6\%) and duration of the program $(20.6 \%)$, but gave a high evaluation of the program from the point of view of the information they had gained (see Table 2).

\subsection{Association of nurses' background factors to their satisfaction with the education program}

The nurses' satisfaction with the education program related to their background factors was mostly related to the nurses' working area. In assessing the education program content, nurses from the first group who worked in a gynecological ward were more satisfied with the information they received on HIV transmission (81.3\%) whereas with those drawn from a 
primary health care center, this dropped to only $31.3 \%$ (statistically significant, $p=.038$ ). The nurses from the gynecological ward were also more satisfied with the program's duration than nurses from medical ward $(p=.003)$ (see Table 3 ). The evaluation of the educational program (from 0 to 10) among the nurses of the first group was not statistically significant as far as the duration was concerned. Program evaluation (from 0 to 10 ) was affected by the nurses' working areas: $68.8 \%$ of the nurses in the first group who worked in the gynecological ward evaluated the program with the highest mark (10), while only $6.7 \%$ of the nurses from the surgical ward evaluated the program with the highest mark (10). The result was statistically significant $p=.004$.

Table 2. Satisfaction with the education program at follow-up

\begin{tabular}{|c|c|c|c|c|c|c|}
\hline \multirow[t]{2}{*}{ Proposition (\%) } & Very satisfied & Satisfied & $\begin{array}{l}\text { Partly satisfied } \\
\text { partly dissatisfied }\end{array}$ & Dissatisfied & $\begin{array}{l}\text { Very } \\
\text { dissatisfied }\end{array}$ & \multirow[t]{2}{*}{$\boldsymbol{P}$} \\
\hline & First/second & First/second & First/second & First/second & First/second & \\
\hline The content: & $39.7 / 46.0$ & $60.3 / 54.0$ & & & & .473 \\
\hline $\begin{array}{l}\text { HIV epidemiology } \\
\text { and history }\end{array}$ & $41.3 / 54.0$ & $55.6 / 38.1$ & $3.2 / 7.9$ & & & .301 \\
\hline Legislation & $38.1 / 44.4$ & $52.4 / 34.9$ & $7.9 / 17.5$ & $1.6 / 1.6$ & $0 / 1.6$ & .905 \\
\hline HIV/AIDS disease & $47.6 / 58.7$ & $52.4 / 39.2$ & $0 / 1.6$ & & & .251 \\
\hline HIV transmission & $57.1 / 68.3$ & $42.9 / 31.7$ & & & & .199 \\
\hline Co-Infection & $41.3 / 52 / 4$ & $54.0 / 36.5$ & $4.8 / 11.1$ & & & .459 \\
\hline Treatment and care & $61.9 / 66.7$ & $34.9 / 33.3$ & $1.6 / 0$ & $1.6 / 0$ & & .499 \\
\hline HIV test & $47.6 / 47.6$ & $46.0 / 44.4$ & $6.3 / 6.3$ & $0 / 1.6$ & & .920 \\
\hline Risk contact & $61.9 / 58.7$ & $34.9 / 34.9$ & $3.2 / 6.3$ & & & .629 \\
\hline Post-exposition prophylaxis & $46.0 / 46.0$ & $42.9 / 34.9$ & $11.1 / 19.0$ & & & .651 \\
\hline Disclosure/confidentiality & $57.1 / 47.6$ & $41.3 / 42.9$ & $1.6 / 9.5$ & & & .162 \\
\hline Stigma/discrimination & $49.2 / 44.4$ & $38.1 / 36.5$ & $11.1 / 12.7$ & $1.6 / 3.2$ & $0 / 3.2$ & .403 \\
\hline Fear of contagion & $57.1 / 57.1$ & $31.7 / 36.5$ & $9.5 / 3.2$ & $1.6 / 3.2$ & & .844 \\
\hline Moral issues & $44.4 / 47.6$ & $46.0 / 38.1$ & $7.9 / 12.7$ & $1.6 / 1.6$ & & .974 \\
\hline Ethical issues & $34.9 / 46.1$ & $57.1 / 38.1$ & $6.3 / 14.3$ & $1.6 / 1.6$ & & .580 \\
\hline The methods: & $69.8 / 20.6$ & $28.6 / 52.4$ & $1.6 / 27.0$ & & & $<.001$ \\
\hline Lectures & 63.5 & 36.5 & & & & \\
\hline Group discussions & 66.7 & 27.0 & 6.3 & & & \\
\hline Film about HIV demonstration & 71.4 & 28.6 & & & & \\
\hline $\begin{array}{l}\text { Group discussions with HIV } \\
\text { positive }\end{array}$ & 71.4 & 20.6 & 4.8 & 3.2 & & \\
\hline Written material & $61.9 / 27.0$ & $33.3 / 63.5$ & $4.8 / 7.9$ & $0 / 1.6$ & & $<.001$ \\
\hline The duration of the program & $41.3 / 20.6$ & $27.0 / 15.9$ & $30.2 / 17.5$ & $1.6 / 25.4$ & $0 / 20.6$ & $<.001$ \\
\hline The value for me: & $73.0 / 49.2$ & $23.8 / 49.2$ & $3.2 / 1.6$ & & & .010 \\
\hline Beneficial now & $71.4 / 37.1$ & $27.0 / 41.3$ & $1.6 / 1.6$ & & & .102 \\
\hline Beneficial for future & $65.1 / 52.4$ & $33.3 / 44.4$ & $1.6 / 3.2$ & & & .141 \\
\hline Promote critical thinking & $63.5 / 47.6$ & $34.9 / 46.0$ & $1.6 / 4.8$ & $0 / 1.6$ & & .055 \\
\hline
\end{tabular}

Note. First group (2-day workshop and written material); second group (written material). Kruskal Wallis Test - the mean difference is significant at the level of $p<.05$.

Nurses from the second group (provided with only written material) who worked in a primary health care center were more satisfied with the HIV and AIDS disease content, than nurses who worked in the gynecological ward $(p=.033)$. However, nurses who worked in the gynecological ward were not at all satisfied with the program duration, whereas $43.8 \%$ of nurses from the medical ward were satisfied with the duration of the program.

The comparison between the two groups evaluating the education program about HIV and AIDS in the interval scale from 0 to 10 was statistically significant $(p=.016)$. The nurses of the first group evaluated the education program very highly (see Table 3). 
Table 3. The comparison between the two groups in evaluating the education program on an interval scale from 0-10

\begin{tabular}{lllllllll}
\hline $\mathbf{( \% )}$ & $\mathbf{4}$ & $\mathbf{5}$ & $\mathbf{6}$ & $\mathbf{7}$ & $\mathbf{8}$ & $\mathbf{9}$ & $\mathbf{1 0}$ & $\mathbf{P}$ \\
\hline First group & 0 & 1.6 & 1.6 & 6.3 & 27.9 & 28.6 & 34.9 & .016 \\
Second group & 1.6 & 11.1 & 1.6 & 15.9 & 22.2 & 23.8 & 23.8 & \\
\hline
\end{tabular}

Note. First group (2-day workshop and the written material); Second group (the written material). The mean difference is significant at the level of $p$ $<.05$.

\subsection{Nurses' suggestions for future development of the education programs}

In total, of 185 participants from the follow-up questionnaire, 25 nurses reported ways in which education programs may be further developed (see Table 4), received from all the participating groups. Most suggestions concerned program methods and program duration. The nurses of the first group (2-day workshop and the provision of written materials) indicated that they would like to have courses with lectures using more visual means of presenting material, more discussions, and that the courses should be longer.

The nurses of the second group (provision of written materials only) indicated that the courses should be provided regularly (2-3 times per year) and that the distribution of materials should be made easier and in a more imaginative manner. They also wanted to have longer-term courses. Similar suggestions were highlighted by the nurses of the control group (regarding the education program method and duration).

Table 4. Nurses' suggestions regarding the future development of education program

\begin{tabular}{llll}
\hline Methods: & First group $\left(\mathbf{N}^{*}\right)$ & Second group $\left(\mathbf{N}^{*}\right)$ & Control group $\left(\mathbf{N}^{*}\right)$ \\
\hline Lectures & 3 & 8 & 2 \\
Discussion & 1 & - & - \\
Visual (e.g. film) & 1 & - & - \\
Distribution material & - & 2 & - \\
Program duration & 2 & 2 & 5 \\
\hline
\end{tabular}

Note. First group (2-day workshop and the written material); Second group (the written material). ${ }^{*} \mathrm{~N}-$ the number of answers

\section{Discussion}

The best information source for HIV or/and AIDS related information in the present study was reported to be a special course. This was expressed by both groups in the surveys conducted before and after the education program. The finding coincides with studies by Pisal et al. ${ }^{[28]}$ Williams et al. ${ }^{[29]}$ and Endacott et al. ${ }^{[30]}$. The study by Timmins ${ }^{[2]}$ indicated that nurses gave priority to conferences and nursing journals in the process of renewing their knowledge.

The nurses of the first group evaluated the best possible duration of an HIV and AIDS education program to be 2-5 days and the second group - more than 1 week. This finding is similar to that of, e.g. Pisal et al. ${ }^{[28]}$ Williams et al. ${ }^{[29]}$ Charuluxananan et al. ${ }^{[31]}$ and Brunero et al. ${ }^{[32]}$ who reviewed the educational programs in nursing found that statistically significant results were evident from the shorter duration studies of 11 hours, with the longest program of 105 hours showing only trend improvement.

Following the education program, the nurses of the first group were more satisfied with the content areas of risk contact and treatment and care. The nurses of the second group were more satisfied with HIV transmission and treatment, and care explanation they read from the posted material. The satisfaction differences among nurses from different clinical areas challenges the managers. It is obvious the nurses' knowledge level should be added, but how to do that in appropriate way. The general course like in this study are more economic, but at the same time can't reach all as well nurses working in 
surgical, medical, or gynecology wards and primary health care centers. The reason to have these nurses in our study was based on the knowledge they most often meet HIV-infected people and are in frontline to receive additional education also in a country where the topic has been not of interest earlier so much in continuing education and lacks health care development money. Nurses from different clinical areas have specific education needs concerned their everyday nursing practice. Realistic way is not though have a special course to all clinical areas, but some combination of general part and more specific part of the content areas based on clinical areas would be welcomed in countries with low economic situation.

The first and second group opinions were very different when assessing the education program methods, yet both groups highly rated the input they received during the educational programs. In previous literature, researchers who described intervention studies in a similar context ${ }^{[28,29]}$ did not examine the levels of nurses' satisfaction with, for example, the program methods or content.

Statistically, nurses' satisfaction with the educational program was mostly related to the background factors that associated with the nurse's working area. However, when offering ideas about the future development of educational programs, nurses emphasized the importance of program methods and duration, but did not offer more detailed information which kind of content additions they wanted in the program.

\section{Conclusions}

The present study indicated that the best information source for HIV or/and AIDS related information was reported to be a special course, and the best possible duration of HIV and AIDS -related education program to be 2-5 days, or more than 1 week. In future studies researches should examine not only the effectiveness of the programs in changing knowledge, attitudes and willingness to care in the short term, but also the nurses' satisfaction with the program. In doing so, it may be possible to identify obstacles which nurses encounter in local educational programs and give rise to the development of effective strategies by which they may be overcome.

\section{Acknowledgements}

The researchers would like to thank the Finnish Nursing Education Foundation for their financial support. We would also like to thank the nurses in Lithuania and others for their contribution to this study.

\section{References}

[1] Gallagher L. Continuing education in nursing: a concept analysis. Nurse Educ Today. 2007; 27: 466-473. PMid:17109998 http://dx.doi.org/10.1016/j.nedt.2006.08.007

[2] Timmins F. Cardiac nurses' views of continuing professional education. Eur J Cardiovasc Nurs. 2008; 7: 59-66. PMid:17716948 http://dx.doi.org/10.1016/j.ejcnurse.2007.07.007

[3] Bartels JE. Educating nurses for the 21st century. Nurs Health Sci. 2005; 7: 221-225. PMid:16271127 http://dx.doi.org/10.1111/j.1442-2018.2005.00249.x

[4] O'Brien MA, Freemantle N, Oxman AD, Wolfe F, Davis D, Herrin J. Continuing education meetings and workshops: effects on professional practice and health care outcomes (Review). Cochrane Database Syst Rev, Issue 1, 2009.

[5] Cannon S, Boswell C. Filling gaps in knowledge: educating nurses to provide appropriate patient materials. J Contin Educ Nurs. 2009; 40(4): 148-149. http://dx.doi.org/10.3928/00220124-20090401-01

[6] Skees J. Continuing education: a bridge to excellence in critical care nursing. Crit Care Nurs Q. 2010; 33(2): $104-116$. PMid:20234199 http://dx.doi.org/10.1097/CNQ.0b013e3181d913a1

[7] Mugisha JF. Interaction of Continuing Professional Development, Organisational Culture and Performance in Health Service Organisations: A Concept Paper. Health Policy and Development Journal. 2009; 7(1): 51-59.

[8] Billings DM, Kowalski K. Using webcasts for continuing education in nursing. J Contin Educ Nurs. 2007; $38(4): 152-153$. PMid:17708113 
[9] Sweeney NM, Saarmann L, Flagg J, Seidman R. The keys to successful online continuing education programs for nursing. J Contin Educ Nurs. 2008; 39: 34-41. PMid:18286929 http://dx.doi.org/10.3928/00220124-20080101-09

[10] Brooker C, Saul C, Robinson J, King J, Dudley M. Is training in psychosocial interventions worthwhile? Report of a psychosocial intervention trainee follow-up study. Int J Nurs Stud. 2003; 40(7): 731-747. http://dx.doi.org/10.1016/S0020-7489(03)00013-0

[11] Greenawald DA, Adams TM. School nurse book clubs: an innovative strategy for lifelong learning. J Sch Nurs. 2008 ; $24: 61-65$. http://dx.doi.org/10.1177/10598405080240020201

[12] Gopee N. Lifelong learning in nursing: perceptions and realities. Nurse Educ Today. 2001; 21: 607-615. PMid:11884173 http://dx.doi.org/10.1054/nedt.2001.0670

[13] Giddens J, Brady D. Rescuing nursing education from content saturation: The case for a concept-based curriculum. J Nurs Educ. 2007; 46(2): 65-69. PMid:17315564

[14] Kowalski K.M, Vaught C. Principles of adult learning: Application for mine trainers. National Institute for Occupational Safety and Health (NIOSH) Information Circular. 2002; 9463: 3-8.

[15] Drey N, Gould D, Allan T. The relationship between continuing professional education and commitment to nursing. Nurse Educ Today. 2009; 29: 740-745. PMid:19394724 http://dx.doi.org/10.1016/j.nedt.2009.03.008

[16] Hegney D, Tuckett A, Parker D, Robert E. Access to and support for continuing professional education amongst Queensland nurses: 2004 and 2007. Nurse Educ Today. 2010; (30):142-149. PMid:19646799 http://dx.doi.org/10.1016/j.nedt.2009.06.015

[17] White K, Eagle J, McNeil H, Dance S, Evans LA, Harris H, Reid MJ. What are the factors that influence learning in relation to nursing practice? J Nurses Staff Dev. 1998; 14(3): 147-153. PMid:9679072 http://dx.doi.org/10.1097/00124645-199805000-00006

[18] Halcomb E, Meadley E, Streeter S. Professional development needs of general practice nurses. Contemp Nurse. 2009; 32(1-2): 201-210. PMid:19697990 http://dx.doi.org/10.5172/conu.32.1-2.201

[19] Pullon S, Fry B. Interprofessional postgraduate education in primary health care: Is it making a difference? J Interprof Care. 2005; 19(6): 569-578. PMid:16373213 http://dx.doi.org/10.1080/13561820500448209

[20] Carey N, Courtenay M. An exploration of the continuing professional development needs of nurse independent prescribers and nurse supplementary prescribers who prescribe medicines for patients with diabetes. J Clin Nurs. 2010; 19: $208-216$. PMid:20500258 http://dx.doi.org/10.1111/j.1365-2702.2009.02943.x

[21] Čaplinskas S. Epidemiology of HIV/AIDS in Lithuania in 1988-2001: Review of present situation and prognosis of HIV transmission trends. Medicina. 2004; 20(2): 161-168.

[22] Liljestrand P. HIV care: continuing medical education and consultation needs of nurses, physicians, and pharmacists. JANAC. 2004; 15(2): 8-50.

[23] Mullins IL. How caring for persons with HIV/AIDS affects rural nurses? Issues Ment Health Nurs. 2009; 230(5): $311-319$. PMid:19437250 http://dx.doi.org/10.1080/01612840902754461

[24] Mbanya DN, Zebaze R, Kengne AP, Minkoulou EM, Awah P, Beure. Knowledge, attitudes and practices of nursing staff in a rural hospital of Cameroon: How much does the health care provider know about the human immunodeficiency virus/acquired immune deficiency syndrome? Int Nurs Rev. 2001; 48(4): 241-249. PMid:11775758 http://dx.doi.org/10.1046/j.1466-7657.2001.00090.x

[25] Ezedinachi EN, Ross MW, Meremiku M, Essien EJ, Edem CB, Ekure E, Ita O. The impact of an intervention to change health workers' HIV/AIDS attitudes and knowledge in Nigeria: A controlled trial. Public Health. 2002; 116(2): 106-112. PMid:11961679

[26] LoBiondo-Wood G, Haber J. Nursing research: methods, critical appraisal, and utilization. St Louis, Mosby; 2002; $365-382$.

[27] Burns N, Grove S.K. The Practice of Nursing Research. Conduct, Critique and Utilization. 5th ed. WB. Philadelphia: Saunders Company; 2005.

[28] Pisal H, Sutar S, Sastry J, Kapadia-Kundu N, Joshi A, Joshi M, et al. Nurses health education programme in India increases HIV knowledge and reduces fear. JANAC. 2007; 18(6): 32-43. PMid:17991597

[29] Williams AB, Wang H, Burgess J, Wu C, Gong Y, Li Y. Effectiveness of an HIV/AIDS educational programme for Chinese nurses. J Adv Nurs. 2006; 53(6): 710-720. PMid:16553679 http://dx.doi.org/10.1111/j.1365-2648.2006.03777.x

[30] Endacott R, Scholes J, Chellel A. Balancing stakeholder needs: a review of ENB 100 and 415 courses. Intensive Crit Care Nurs. 2000; 16(1): 3-12. PMid:10790710 http://dx.doi.org/10.1054/iccn.2000.1471

[31] Charuluxananan S, Somboonviboon W, Kunthollaxami A, Migasena R, Chinachot T. Effect of national seminar on AIDS and anesthesia upon knowledge, attitude and practice concerning HIV among Thai anesthesia personnel. J Med Assoc Thai. 2000; 83(2): 174-181. PMid:10710887

[32] Brunero, S., Lamont S., Coates, M. A review of empathy education in nursing. Nurs Inq. 2010; 17(1): 65-74. PMid:20137032 http://dx.doi.org/10.1111/j.1440-1800.2009.00482.x 